Editorial

\title{
The Shared Socio-economic Pathways: Trajectories for human development and global environmental change
}

\section{Introduction}

This Special Issue presents the Shared Socioeconomic Pathways (SSPs), a set of five storylines on possible trajectories for human development and global environmental change during the 21st century. The SSPs represent an unique product, forming the most comprehensive set of scenarios for environmental and sustainable development research produced so-far. Each SSPs consists of a narrative of future socio-economic development as well as quantitative data generated by state-of-the-art demographic, economic and integrated assessment models illustrating the narratives. The quantitative information includes projections on wide range of topics such population size, urbanization rates, income, energy use and production, agriculture and land use, emissions and climate change. Together, the set provides information on a wide ranges of futures ranging from those more consistent with sustainable development trends to futures characterized by a strong increase in resource consumption rates, environmental pressure and large challenges with respect to human development. The SSPs can be used in climate change research as well as in other research areas such as biodiversity and sustainable development.

The SSPs have been developed over the last few years as a joint community effort and form part of a larger set of community scenarios for analysis of climate change, global environmental change and sustainable development issues. Together, these scenarios allow exploration of different futures with and without climate policy responses. The SSPs are intended to form a key tool to link climate change research across different disciplines, from the driving forces of climate change to the physical climate system, climate impacts and adaptation and mitigation strategies. They can also be used across different geographical scales (global, regional and local scales) (Absar and Preston, 2015) or to link different sectors. In that context, the global scenarios presented in this Special Issue can be used at the local scale or for specific sectors as a boundary condition, as a "wind tunnel" to explore consistency, or more loosely based on the storylines. The SSPs can also link different research areas to climate change projections (linking biodiversity and climate change analysis, (Kok et al., 2016)). Finally, they also have a key function as a consistent data source (e.g. for population projections, climate projections and insights into land and energy development).

In 2010, Moss et al. (2010) described a strategy to develop new community scenarios to replace the SRES scenarios, which were published in 2000 and developed in the late 1990s. A first step in this strategy involved the development of the Representative Concentration Pathways (RCPs). The RCPs consist of a set of pathways for emissions and concentrations of greenhouse gases and air pollutants as well as for land use (van Vuuren et al., 2011) and the subsequent changes in the climate system (Taylor et al., 2012). In 2014, several papers (Kriegler et al., 2014; O’Neill et al., 2014; van Vuuren et al., 2014) described the conceptual framework of how the RCPs could be combined with the SSPs. To this end, a scenario matrix approach was introduced that facilitates the research community to conduct integrated climate change assessments. This consistent framework to assess various response strategies to climate change provides the basis for the elaboration of the SSPs.

This special issue takes the next step in this process and provides a detailed description of the content of the SSPs. The overview paper by Riahi et al. (2017) describes the main characteristics of the SSPs. It focuses on how the SSPs have been designed in order to provide a description of plausible human development strategies that lead to very different future challenges with respect to mitigation and adaptation to climate change. It also summarizes the global average forcing and climate consequences as projected with a simple climate model. The overview paper is complemented by more detailed papers on different components of the SSPs, including particularly the SSP narratives (O'Neill et al., 2017), quantitative descriptions for key scenario drivers such as population (KC and Lutz, 2017), three alternative economic growth prospects (Crespo Cuaresma, 2017; Dellink et al., 2017; Leimbach et al., 2017), and urbanization (Jiang and O'Neill, 2017). Five individual papers describe the main dynamics of each SSP scenario (Calvin et al., 2017; Fricko et al., 2017; Fujimori et al., 2017; Kriegler et al., 2017; van Vuuren et al., 


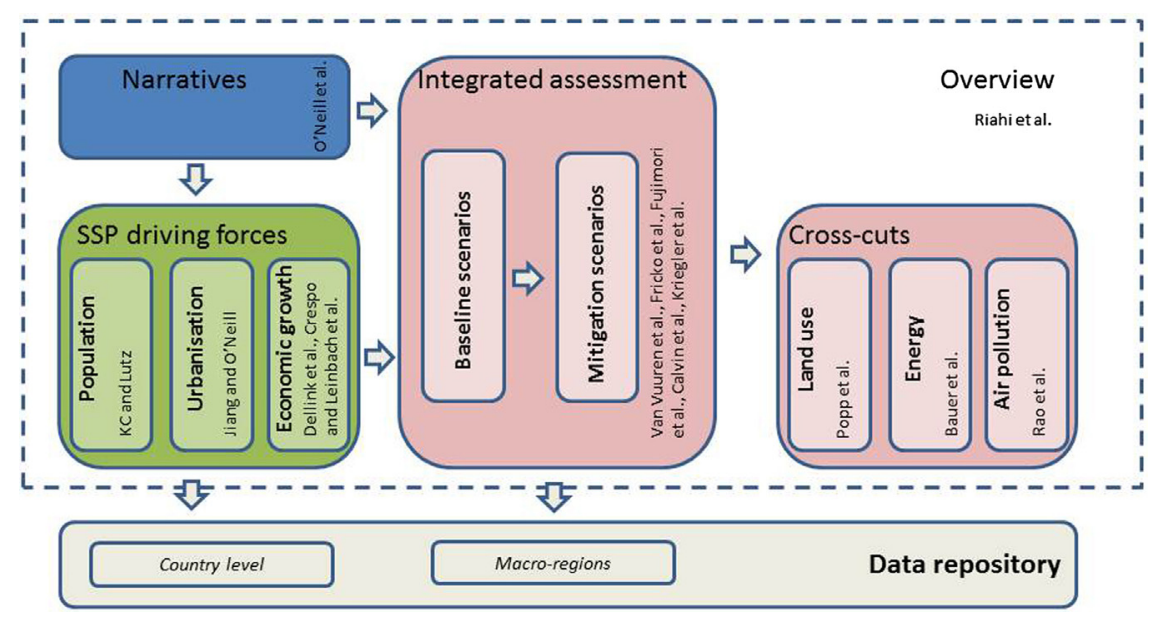

Fig. 1. Overview of the Special Issue and how the different outcomes of the SI papers feed into a community database on the SSPs.

2017). Dedicated cross-cut papers elaborate the SSPs in terms of the energy system, land-use changes, and resulting air pollutant emissions (Bauer et al., 2017; Popp et al., 2017; Rao et al., 2017). Fig. 1 shows how the papers in this Special Issue are connected in order to provide a comprehensive account of the SSPs. In the remaining part of this editorial, we discuss briefly how the different papers of the Special Issue connect to form one consistent and detailed story about the SSPs.

\section{Brief introduction into the different papers}

\subsection{An overview of the SSPS}

The paper by Riahi et al. (2017) provides an overview of the SSPs, in terms of their main characteristics, but also in terms of development process and methodology. Specifically the paper describes how the narratives were translated into quantitative descriptions for key scenario drivers, such as population, economic growth, and urbanization, which provided the foundation for the elaboration of the SSP-based scenarios in terms of energy system and land-use changes, as well as resulting air pollutant and greenhouse gas emissions, atmospheric concentrations and climate change. The SSP scenarios consist of a set of baselines, which provide a description of future developments in absence of climate change impacts or of new climate policies beyond those in place today, as well as mitigation scenarios, which explore the implications of climate change mitigation policies. An important asset of the SSP development process is the multi-model approach that was employed for the quantification of the SSP characteristics and their associated uncertainties. Among the alternative model interpretations, so-called "marker" SSPs were selected as representative of the specific SSP developments. Riahi and colleagues conclude with important implications of the SSPs for their further use in other assessments, and provide an outlook in terms of future research that might build upon the marker SSP projections provided in this special issue.

\subsection{SSP narratives}

The narratives are an important element of the SSPs. These narratives form a set of consistent, qualitative descriptions of future changes in demographics, human development, economy and lifestyle, policies and institutions, technology, and environment and natural resources. The narratives are intended as a description of plausible future conditions at the level of large world regions that can serve as a basis for integrated scenarios of emissions and land use, as well as climate mitigation, impact, adaptation and vulnerability analyses. They were designed to cover a range of socioeconomic challenges to mitigate and adapt to climate change, but also describe a set of worlds with very different development implications. The paper by O'Neill et al. provides a detailed description of these narratives (named Sustainability, Regional Rivalry, Inequality, and Fossil-fueled Development, and a Middle of the Road pathway). It shows how the development of the narratives drew on expert opinion to (1) identify key determinants of these challenges that were essential to incorporate in the narratives and (2) combine these elements in the narratives in a manner consistent with scholarship on their inter-relationships.

\subsection{Demographic and economic drivers}

Population and economic growth form key determinants of further changes in energy and land-use. Four papers in the Special Issue describe how quantitative scenarios for these elements were developed. First, the paper by KC et al. describes a set of national population projections based on alternative demographic assumptions. The population scenarios are not only differentiated by age and sex -as is conventionally done in demographic projections-but also by different levels of educational attainment, addressing a fundamental aspects of human development and social change. The scenarios show that the total world population size of the five SSPs are very similar until around 2030, but the range widens after 2030 with the SSP3 reaching 12.6 billion in 2100 and SSP1 falling to 6.9 billion in 2100.

Three different papers by Dellink et al., Crespo et al., and Leimbach et al. describe the possible long-term economic developments. They are developed using different economic tools. The paper by Dellink et al. describes a consistent methodology to derive GDP scenarios using the OECD ENV-Growth model. The methodology is based on a conditional convergence process and places emphasis on the key drivers of economic growth in the long run: population, total factor productivity, physical capital, employment and human capital, and energy resources. The paper by Crespo et al., instead, discusses how the 
robust link between educational attainment, age structure dynamics and economic growth can be used to derive a set of income projections. Finally, the economic projections of Leimbach et al. are based on assumptions about technological progress, human and physical capital formation and different levels of convergence between regions. In the SSP process, the outcomes of the OECD ENV-Growth model were selected as "marker scenarios" while the other projections can be used to shed light on the large uncertainty in different economic growth rates. All projections of the marker scenarios were made at the national level and are available in the SSP scenario database. At the global average, the GDP per capita growth rate projections cover a wide range from $1.0 \%$ p.a. (SSP3) and 2.8\% p.a. (SSP5) from 2010 to 2100 (still, plausible lower and higher growth projections may be conceivable).

Finally, the paper by Jiang and O'Neill looks into different urbanization pathways for the SSPs. These pathways are a consistent set of global urbanization projections over long time horizons that span a wide range of uncertainty. This is unique, as existing urbanization projections often provide only a single scenario over the next few decades. Results show that the world continues to urbanize in each of the SSPs but outcomes differ widely across them, with urbanization reaching $60-90 \%$ globally by the end of century across the range of SSPs.

\subsection{Integrated assessment modeling}

Different Integrated Assessment Models (IAMs) were used to derive quantitative scenarios on trends in energy consumption and production, agricultural development and land use, emissions and associated changes in climate based on the five SSPs. This did not only include SSP baseline scenarios without climate policy intervention, but also SSP policy scenarios looking into the consequences of climate policy reaching forcing levels consistent with the RCPs and a newly analysed forcing level of $3.4 \mathrm{~W} / \mathrm{m}^{2}$. Each IAM implemented several SSPs. This allowed to evaluate some of the key uncertainties for each SSP given the different character of the models and the different interpretation of the storylines by the associated model groups. For each SSP, however, one model was chosen to represent the marker scenario - as this elaboration was found to represent the storyline of the SSP very well. The papers (Calvin et al., 2017; Fricko et al., 2017; Fujimori et al., 2017; Kriegler et al., 2017; van Vuuren et al., 2017) describe the implementation of the SSPs by the GCAM, MESSAGE/GLOBIOM, AIM, REMIND/MAgPIE and IMAGE modeling frameworks. Each of the papers also describes a specific SSP marker scenario and compares the outcomes of these marker scenarios to alternative elaborations of the other teams.

The paper by Van Vuuren et al. describes the possible developments in global energy use and production, land use, emissions and climate changes following the SSP1 storyline. The results show that a combination of resource efficiency, preferences for sustainable production methods and investment in human development could lead to a strong transition towards a more renewable energy supply, less land use and lower anthropogenic greenhouse gas emissions in 2100 than in 2010, even in the absence of explicit climate policies. The SSP1 storyline could be a basis for further discussions on how climate policy can be combined with achieving other societal goals. The paper by Fricko et al. discusses the implementation of the SSP2 narrative. The paper shows that the SSP2 marker implementation occupies a central position for key metrics along the mitigation and adaptation challenge dimensions. For many dimensions the SSP2 marker implementation also reflects an extension of historical experience, particularly in terms of carbon and energy intensity improvements in its baseline. The paper by Fujimori et al. focuses on the SSP3 marker scenario. Four key features of this scenario, according to this paper, are the relatively high costs to reach ambitious climate targets, the medium-high forcing level for the reference scenario, the high air pollutant emissions, and the decrease of forest area as a result of rapid expansion of cropland and pasture land. This means that the SSP3 is useful for both IAM and impact, adaptation, vulnerability (IAV) analyses, presenting a pessimistic scenario (based on both socioeconomic drivers and environmental conditions). The high air pollutant emissions are interesting to analyse the high-end range of impacts of air pollution and possible synergies of integrated policies, while many other environmental studies could benefit from the meaningful insights available from the large-scale land use change resulting in SSP3. The paper by Calvin et al. focuses on SSP4. In the SSP4 scenario, high-income communities continue to prosper, while low-income communities are assumed to experience limited economic growth, giving rise to increasing inequalities between and within regions. The globally well connected high income groups continue to increase their demand for energy and food, with increased electrification driven by nuclear and renewables in many regions. The effects of mitigation effort were also explored in the SSP4 world, finding that the imposition of a carbon price has a varied effect across regions. In particular, the SSP4 mitigation scenarios are characterized by afforestation in the high-income regions and deforestation in the low-income regions. The paper by Kriegler et al., finally, presents the SSP5 storyline in more detail. The SSP5 scenario has rapid economic growth, very high levels of fossil fuel use, a doubling of food demand, and a tripling of energy demand and greenhouse gas emissions over the course of the century, marking the upper end of the scenario literature in several dimensions. The SSP5 scenario provides a useful reference points for climate impact and adaptation analysis at high levels of future climate change although climate policy in SSP5 could also significantly reduce emissions.

\subsection{Energy, land use and air pollution cross-cuts}

Three papers looked into comparing SSPs with respect to the key dimensions of energy system development, land use and air pollution, providing a more detailed description for each of these important dimensions of global environmental change (as these papers were written during the SSP process, their in-depth analysis also allowed a discussion of the interpretation of each SSP among the different modeling teams). Bauer et al. (2017) looks into energy system developments across the SSPs. The paper discusses how, across the SSPs, the energy system develops in fundamentally different directions given the differences in socioeconomic conditions and drivers, available energy resources, technologies of energy supply and transformation, and end-use energy demand. As a result, the highest baseline $\mathrm{CO}_{2}$-emissions from fossil fuel combustion are five times larger than the lowest as the most energy-intensive SSP also incorporates a comparatively high share of carbon-intensive fossil fuels, and vice versa. It also shows how the mitigation challenge strongly corresponds with global baseline energy sector growth over the 21th century. Popp et al. (2017) looks into the land-use development across the SSPs using the outcomes of five alternative IAMs. The model results show how global agricultural land could develop from 4.9 Gha in 2005 to a total range of around 4.1 Gha (SSP1) to 6.0 Gha (SSP3) in 2100. The paper also shows how greenhouse gas emissions differ strongly across SSPs and discusses the influence of land-based mitigation efforts, such as bio-energy and reforestation. The SSP-based land use pathways could support future climate research and provide the basis for further regional integrated assessments, biodiversity research and climate impact analysis. Rao et al. (2017) looks into 
the trends in emissions of air pollutants and particulates (such as sulfur and nitrogen oxides) across the SSPs. In the paper, Rao et al. discuss how air pollutant emission projections were introduced in the SSPs, based on air pollution narratives that describe high, central, and low pollution control ambitions over the 21 st century which were next translated into quantitative guidance for use in IAMs. The resulting pollutant emission trajectories under the SSP scenarios cover a wider range than the scenarios used in previous international climate model comparisons.

\section{Final thoughts}

The SSPs as presented in the papers in this Special Issue present different representations of possible future human development, using internally consistent sets of qualitative and quantitative projections. The SSPs provide a wide range of different futures driven by different assumptions on population, economic growth, consumption and production patterns and technology development. They can be used in the coming years as part of climate research and form a basis for future assessment reports. The scenarios will also form a key input into analysis using a new generation of earth system models as part of the 6 th coupled model inter-comparison project (CMIP6) (Eyring et al., 2016; O'Neill et al., 2016). They can also be used in other research communities as the scenario elements can provide important insights into for instance changes in ecosystem services, water scarcity or, even more fundamental, sustainable development. For instance, the SSP scenarios can provide a useful backbone to quantify pathways for the Sustainable Development Goals.

However, it is also clear that further work can increase our insights into possible future development. Such work may go beyond the SSPs as presented here in several ways. First, models can further elaborate the SSP narratives, and the SSP scenario database will be open for submissions of new quantifications in order to provide a richer description of uncertainty. Model comparison studies and studies looking into the underlying causes of the range of result can help to further understand this uncertainty. Second, studies may extend the SSPs into new areas, for instance, at the local scale or for new topics. Third, variants of the SSPs, or altogether new ones, might be developed to better address new research questions. Finally, studies may try to incorporate the possible feedbacks of environmental change on the scenario drivers (the so-called integration phase). The paper by Riahi et al. (2017) discusses the research agenda beyond this Special Issue in more detail.

\section{Acknowledgements}

The authors thank all authors of the Special Issue for their contribution to the papers. RD notes that this paper does not necessarily represent the views of the OECD or its member countries.

\section{References}

Absar, S.M., Preston, B.L., 2015. Extending the Shared Socioeconomic Pathways for sub-national impacts, adaptation, and vulnerability studies. Global Environ. Change 33, 83-96.

Bauer, N., Calvin, K., Emmerling, J., Fricko, O., Fujimori, S., Hilaire, J., Eom, J., Krey, V., Kriegler, E., Mouratiadou, I., De Boer, H.S., van Den Berg, M., Carrara, S., Drouet L., Edmonds, J., Gernaat, D., Harmsen, M., Havlik, P., Johnson, N., Kyle, P., Luderer, G., Marangoni, G., Masui, T., Strefler, J., Strubegger, M., Wise, M., Riahi, K., van Vuuren, D.P., 2017. Shared Socio-economic Pathways of the energy sector -quantifying the narratives. Global Environ. Change 42, 316-330. doi:http://dx. doi.org/10.1016/j.gloenvcha.2016.07.006.
Calvin, K., Bond-Lamberty, B., Clarke, L., Edmonds, J., Eom, J., Hartin, C., Kim, S., Kyle, P., Moss, R., McJeon, H., Patel, P., Smith, S., Waldhoff, S., Wise, M., 2017. SSP4: A world of inequality. Global Environ. Change 42, 284-296. doi:http://dx.doi.org/ 10.1016/j.gloenvcha.2016.06.010.

Crespo Cuaresma, J., 2017. Income projections for climate change research: a framework based on human capital dynamics. Global Environ. Change 42, $226-$ 236. doi:http://dx.doi.org/10.1016/j.gloenvcha.2015.02.012.

Dellink, R., Chateau, J., Lanzi, E., Magné, B., 2017. Long-term economic growth projections in the Shared Socioeconomic Pathways. Global Environ. Change

Eyring, V., Bony, S., Meehl, G.A., Senior, C.A., Stevens, B., Stouffer, R.J., Taylor, K.E., 2016. Overview of the coupled model intercomparison project phase 6 (CMIP6) experimental design and organization. Geosci. Model Dev. doi:http://dx.doi. org/10.5194/gmd-5199-1937-2016.

Fricko, O., Havlik, P., Rogelj, J., Riahi, K., Klimont, Z., Gusti, M., Johnson, N., Kolp, P., Strubegger, M., Valin, H., Amann, M., Ermolieva, T., Forsell, N., Herrero, M. Heyes, C., Kindermann, G., Krey, V., McCollum, D.L., Obersteiner, M., Pachauri, S., Rao, S., Schmid, E., Schoepp, W., 2017. SSP2: a middle-of-the-road scenario for the 21st century. Global Environ. Change 42, 251-267. doi:http://dx.doi.org/ 10.1016/j.gloenvcha.2016.06.004.

Fujimori, S., Hasegawa, T., Masui, T., Takahashi, K., Silva Herran, D., Dai, H., Hijioka, Y., Kainuma, M., 2017. AIM implementation of Shared Socioeconomic Pathways. Global Environ. Change 42, 268-283. doi:http://dx.doi.org/10.1016/j. gloenvcha.2016.06.009.

Jiang, L., O’Neill, B.C., 2017. Global urbanization projections for the Shared Socioeconomic Pathways. Global Environ. Change 42, 193-199. doi:http://dx doi.org/10.1016/j.gloenvcha.2015.03.008.

KC, S., Lutz, W., 2017. The human core of the shared socioeconomic pathways: population scenarios by age, sex and level of education for all countries to 2100 . Global Environ. Change 42,181-192. doi:http://dx.doi.org/10.1016/j. gloenvcha.2014.06.004.

Kok, M.J.T., Kok, K., Peterson, G.D., Hill, R., Agard, J., Carpenter, S.R., 2016. Biodiversity and ecosystem services require IPBES to take novel approach to scenarios. Sustainability Sci. doi:http://dx.doi.org/10.1007/s11625-11016-10354-11628.

Kriegler, E., Edmonds, J., Hallegatte, S., Ebi, K.L., Kram, T., Riahi, K., Winkler, H., van Vuuren, D.P., 2014. A new scenario framework for climate change research: the concept of shared climate policy assumptions. Clim. Change 122, 401-414.

Kriegler, E., Bauer, N., Popp, A., Humpenöder, F., Leimbach, M., Strefler, J., Baumstark, L., Bodirsky, B., Hilaire, J., Klein, D., Mouratiadou, I., Weindl, I., Bertram, C., Dietrich, J.P., Luderer, G., Pehl, M., Pietzcker, R., Piontek, F., Lotze-Campen, H., Biewald, A., Bonsch, M., Giannousakis, A., Kreidenweis, U., Müller, C., Rolinski, S. Schultes, A., Schwanitz, J., Stefanovic, M., Calvin, K., Emmerling, E., Fujimori, S., Edenhofer, O., 2017. Fossil-fueled development (SSP5): an energy and resource intensive scenario for the 21 st century. Global Environ. Change 42, 297-315. doi:http://dx.doi.org/10.1016/j.gloenvcha.2016.05.015.

Leimbach, M., Kriegler, E., Roming, N., Schwanitz, J., 2017. Future growth patterns of world regions - a GDP scenario approach. Global Environ. Change 42, 215-225. doi:http://dx.doi.org/10.1016/j.gloenvcha.2015.02.005.

Moss, R.H., Edmonds, J.A., Hibbard, K.A., Manning, M.R., Rose, S.K., Van Vuuren, D.P., Carter, T.R., Emori, S., Kainuma, M., Kram, T., Meehl, G.A., Mitchell, J.F.B., Nakicenovic, N., Riahi, K., Smith, S.J., Stouffer, R.J., Thomson, A.M., Weyant, J.P., Wilbanks, T.J., 2010. The next generation of scenarios for climate change research and assessment. Nature 463, 747-756.

O’Neill, B.C., Kriegler, E., Riahi, K., Ebi, K.L., Hallegatte, S., Carter, T.R., Mathur, R., van Vuuren, D.P., 2014. A new scenario framework for climate change research: the concept of shared socioeconomic pathways. Clim. Change 122, 387-400.

O’Neill, B.C., Kriegler, E., Ebi, K.L., Kemp-Benedict, E., Riahi, K., Rothman, D.S., van Ruijven, B.J., van Vuuren, D.P., Birkmann, J., Kok, K., Levy, M., Solecki, W., 2017. The roads ahead: narratives for shared socioeconomic pathways describing world futures in the 21 st century. Global Environ. Change 42, 169-180. doi: http://dx.doi.org/10.1016/j.gloenvcha.2015.01.004.

O’Neill, B.C., Tebaldi, C., van Vuuren, D.P., Eyring, V., Friedlingstein, P., Hurtt, G., Knutti, R., Kriegler, E., Lamarque, J.-F., Lowe, J., Meehl, J., Moss, R., Riahi, K., Sanderson, B.M., 2016. The scenario model intercomparison project (ScenarioMIP) for CMIP6. Geosci. Model Dev. 9, 3461-3482. doi:http://dx.doi. org/10.5194/gmd-2016-5184.

Popp, A., Calvin, K., Fujimori, S., Havlik, P., Humpenöder, F., Stehfest, E., Bodirsky, B., Dietrich, J.P., Doelmann, J., Gusti, M., Hasegawa, T., Kyle, P., Obersteiner, M., Tabeau, A., Takahashi, K., Valin, H., Waldhoff, S., Weindl, I., Wise, M., Kriegler, E., Lotze-Campen, H., Fricko, O., Riahi, K., van Vuuren, D.P., 2017. Land use futures in the shared Socio-Economic Pathways. Global Environ. Change 42, 331-345. doi: http://dx.doi.org/10.1016/j.gloenvcha.2016.10.002.

Rao, S., Klimont, Z., Smith, S.J., Van Dingenen, R., Dentener, F., Bouwman, L., Bodirsky, B., Calvin, K., Drouet, L., Fricko, O., Fujimori, S., Luderer, G., Gernaat, D., Havlik, P., Harmsen, M., Hasegawa, T., Heyes, C., Hilaire, J., Masui, T., Aleluia Reis, L. Stehfest, E., Strefler, J., van der Sluis, S., Tavoni, M., Riahi, K., van Vuuren, D.P., 2017. Future air pollution in the Shared Socio-Economic Pathways. Global Environ. Change 42, 346-358. doi:http://dx.doi.org/10.1016/j. gloenvcha.2016.05.012.

Riahi, K., van Vuuren, D.P., Kriegler, E., Edmonds, J., O’Neill, B., Fujimori, S., Bauer, N., Calvin, K., Dellink, R., Fricko, O., Lutz, W., Popp, A., Crespo Cuaresma, J., Leimbach, M., Kram, T., Rao, S., Emmerling, J., Hasegawa, T., Havlik, P. Humpenöder, F., Aleluia Da Silva, L., Smith, S.J., Stehfest, E., Bosetti, V., Eom, J., Gernaat, D., Masui, T., Rogelj, J., Strefler, J., Drouet, L., Krey, V., Luderer, G., Harmsen, M., Takahashi, K., Wise, M., Baumstark, L., Doelman, J., Kainuma, M., Klimont, Z., Marangoni, G., Moss, R., Lotze-Campen, H., Obersteiner, M., Tabeau, A., Tavoni, M., 2017. The Shared Socio-Economic Pathways and their energy, land 
use and greenhouse gas emissions implications: an overview. Global Environ. Change 42, 153-168. doi:http://dx.doi.org/10.1016/j.gloenvcha.2016.05.009.

Taylor, K.E., Stouffer, R.J., Meehl, G.A., 2012. A summary of the CMIP5 experiment design. Bull. Am. Meteorol. Soc. 93, 485-498.

van Vuuren, D.P., Edmonds, J., Kainuma, M., Riahi, K., Thomson, A., Hibbard, K., Hurtt, G.C., Kram, T., Krey, V., Lamarque, J.F., Masui, T., Meinshausen, M., Nakicenovic, N., Smith, S.J., Rose, S.K., 2011. The representative concentration pathways: an overview. Clim. Change 109, 5-31.

van Vuuren, D.P., Kriegler, E., O’Neill, B.C., Ebi, K.L., Riahi, K., Carter, T.R., Edmonds, J., Hallegatte, S., Kram, T., Mathur, R., Winkler, H., 2014. A new scenario framework for climate change research: scenario matrix architecture. Clim. Change 122, 373-386.

van Vuuren, D.P., Stehfest, E., Gernaat, D., Doelman, J., van Den Berg, M., Harmsen, M., de Boer, H.S., Bouwman, A.F., Daioglou, V., Edelenbosch, O.Y., Girod, B., Kram, T., Lassaletta, L., Lucas, P., van Meijl, H., Müller, C., van Ruijven, B., van der Sluis, S., Tabeau, A., 2017. Energy, land-use and greenhouse gas emissions trajectories under a green growth paradigm. Global Environ. Change 42, 237-250. doi: http://dx.doi.org/10.1016/j.gloenvcha.2016.05.008.

Detlef P. van Vuuren ${ }^{\mathrm{a}, \mathrm{b}, *}$

${ }^{a}$ PBL Netherlands Environmental Assessment Agency, The Hague, The Netherlands

${ }^{b}$ Utrecht University, Copernicus Institute for Sustainable Development, Utrecht, The Netherlands

Keywan Riahi ${ }^{\mathrm{a}, \mathrm{b}}$

${ }^{a}$ International Institute for Applied Systems Analysis (IIASA), Laxenburg, Austria

${ }^{b}$ Graz University of Technology, Graz, Austria

Katherine Calvin

Pacific Northwest National Laboratory, College Park, MD USA, USA
Rob Dellink

OECD, Organisation for Economic Cooperation and Development,

Paris, France

Johannes Emmerling ${ }^{\mathrm{a}, \mathrm{b}}$

${ }^{a}$ FEEM, Fondazione Eni Enrico Mattei, Milan, Italy

${ }^{b}$ Centro Euro-Mediterraneo sui Cambiamenti Climatici (CMCC), Italy

Shinichiro Fujimori

NIES National Institute for Environmental Studies, Tsukuba, Japan

Samir $K C^{\mathrm{a}, \mathrm{b}}$

${ }^{a}$ International Institute for Applied Systems Analysis (IIASA),

Laxenburg, Austria

${ }^{b}$ Shanghai University, Asian Demographic Research Institute, Shanghai, China

Elmar Kriegler

PIK Potsdam Institute for Climate Impact Research, Potsdam,

Germany

Brian O'Neill

NCAR National Centre for Atmospheric Research, Boulder, USA

* Corresponding author at: PBL Netherlands Environmental Assessment Agency, The Hague, The Netherlands. E-mail address: detlef.vanvuuren@pbl.nl (D. van Vuuren).

Received 7 September 2016 